УДК 378.046

\title{
А.Г. Горбунов
}

\section{НЕКОТОРЫЕ АСПЕКТЫ РАЗРАБОТКИ КРИТЕРИАЛЬНО-ДИАГНОСТИЧЕСКОГО АППАРАТА ОЦЕНКИ УРОВНЯ СФОРМИРОВАННОСТИ СПОСОБНОСТИ БУДУЩИХ БАКАЛАВРОВ ГУМАНИТАРНЫХ НАПРАВЛЕНИЙ К ПРОФЕССИОНАЛЬНО- ОРИЕНТИРОВАННОЙ КОММУНИКАЦИИ НА ИНОСТРАННОМ ЯЗЫКЕ}

\begin{abstract}
В контексте постоянно меняющегося образовательного пространства проблема разработки содержания и критериально-диагностических процедур фондов оценочных средств для определения уровня сформированности профессионально значимых компетенций не теряет своей актуальности. В частности, система оценки уровня сформированности способности будущих бакалавров гуманитарных направлений подготовки к профессионально-ориентированной коммуникации на иностранном языке рассмотрена нами с позиции современной педагогической методологии, которая предполагает синергию различных научных знаний. Цель статьи - рассмотреть и описать некоторые аспекты разработки критериально-диагностического аппарата как эффективного инструмента оценки уровня сформированности способности будущих бакалавров к профессионально-ориентированной коммуникации на иностранном языке через восприятие и порождение дискурсов, присущих различным профессиональным сообществам.

Методология исследования. Обзор информационных ресурсов позволил нам прийти к умозаключению о том, что стратегия подачи информации на телевидении, в периодических изданиях, в сети Интернет и в рамках информационных обменов между представителями профессиональных сообществ тяготеет к англоязычной модели речевого взаимодействия. Такая модель линейна, имеет ярко выраженную структуру, жёстко выстроенную внутреннюю логику и характеризуется как завершённое речевое произведение, что позволяет целевой аудитории однозначно декодировать интегрированные в тело локуции смыслы. Последние достижения в сфере прикладной лингвистики позволяют утверждать, что в основе коммуникации лежит способность участников речевого взаимодействия воспринимать и порождать дискурсы. Такой подход к пониманию дискурсивной природы коммуникации позволил нам разработать универсальную систему диагностических процедур, которые в традиционной пятибалльной системе оценки предопределяют возможность обеспечить достоверность и приемлемость оценочных выводов об уровне сформированности дискурсивной иноязычной компетенции будущих бакалавров в качестве дескриптора уровня их способности к профессионально-ориентированной коммуникации на иностранном языке. Результаты и научная новизна. Основанный на синергии данных различных областей науки алгоритм диагностических и оценочных процедур позволяет исследователю получить валидные значения. Алгоритм апробирован в ходе экспериментальной работы и подтвердил свою эффективность. Практическая значимость. Критериально-диагностический аппарат обладает высокой степенью гибкости и предполагает возможность приращения дополнительными оценочными средствами.
\end{abstract}

Ключевые слова: фонд оценочных средств, критериально-диагностический аппарат, оценочные процедуры, коммуникативная иноязычная компетентность, дискурсивная иноязычная компетенция, англоязычная модель речевого взаимодействия.

DOI: $10.35634 / 2412-9550-2019-29-4-478-487$

\section{1. Введение}

Федеральный государственный образовательный стандарт третьего поколения по направлениям подготовки в сфере гуманитарного образования в высшей школе обусловливает высокие требования к уровню и содержанию формируемых компетенций будущих бакалавров гуманитарных направлений подготовки (далее: будущие бакалавры). Оценка уровня сформированности обязательных для таких направлений подготовки компетенций, в числе которых особое место занимает коммуникативная иноязычная компетенция, проводится в соответствии с алгоритмом, задаваемым фондами оценочных средств (ФОС).

Проблема разработки эффективной системы оценочных средств для широкого спектра компетенций актуальна в свете постоянно изменяющегося образовательного контекста и перечня требований к выпускнику высшей профессиональной школы [12]. Необходимость оценки уровня сформированной способности к профессионально-ориентированной коммуникации на иностранном языке обретает особое значение, так как в условиях универсификации информационного пространства и глобализации рынка труда, выпускник вуза рассматривает способность к коммуникации на иностранном языке как инструмент для организации успешного межкультурного взаимодействия и информацион- 
Некоторые аспекты разработки критериально-диагностического аппарата...

ного обмена в целях личностного и профессионального развития и, наконец, как возможность получить карьерные преимущества. Кроме того, продвинутый и высокий уровень способности будущего бакалавра к профессионально-ориентированной коммуникации на иностранном языке обеспечивает ему высокий уровень социальной и профессиональной адаптивности, а также высокую степень академической и трудовой мобильности.

Практический опыт преподавательской работы показывает, что будущие бакалавры испытывают различного рода затруднения в ходе коммуникации на иностранном языке в условиях учебного занятия ввиду отсутствия практики в реализации стратегий построения речевого произведения, вследствие чего эти речевые произведения на иностранном языке «<...> однообразны, стилистически невыразительны, в них изобилуют лексико-грамматические модели, свойственные родному языку. Даже подготовленная речь зачастую малоинформативна. <..> характерны деформация логической структуры исходного текста, провалы в передаче фактологической цепочки, произвольная перестановка смысловых звеньев <...>» [3. С. 11].

Мы полагаем, что в основе готовности современного специалиста к профессиональноориентированной коммуникации на иностранном языке лежит способность к восприятию и производству институциональных дискурсов. Сформированный уровень дискурсивной иноязычной компетенции позволяет воспринимать и порождать профессионально-ориентированные дискурсы и отражает уровень сформированности способности будущих бакалавров к профессионально-ориентированной коммуникации на иностранном языке. Процесс формирования искомой компетенции мы рассматриваем с позиций синергии педагогической науки и прикладной лингвистики. Внедрение в образовательный процесс дискурсивной составляющей обусловливает метапредметный характер коммуникативных умений студентов и способствует формированию образа высоко квалифицированного специалиста.

Так как вузы наделены широкими полномочиями в части определения структуры и содержания фондов оценочных средств, у разработчиков ФОСов из числа профессорско-преподавательского состава есть возможность своевременно вносить дополнения и нововведения в целях совершенствования критериально-диагностического аппарата для объективной оценки уровня сформированности некоторых из системы компетенций на различных направлениях подготовки в сфере гуманитарного образования. В нашем случае содержание ФОСа должно обеспечивать возможность реализации последовательных диагностических процедур с целью определения уровня сформированности дискурсивной иноязычной компетенции как дескриптора их способности к профессионально-ориентированной коммуникации на иностранном языке, что, по нашему мнению, отражает способность студентов на практике воспринимать и производить профессионально-ориентированные дискурсы и позволяет обучающимся успешно решать широкий диапазон коммуникативных задач на иностранном языке в условиях учебного занятия, а также в ходе самостоятельной подготовки и, впоследствии, в ходе взаимодействия с представителями профессиональных сообществ за рубежом.

\section{2. Обзор литературы}

Описание методов разработки критериально-диагностических систем педагогического контроля для измерения уровня сформированности способности будущих бакалавров к профессиональноориентированной коммуникации на иностранном языке через восприятие и порождение дискурсов, присущих различным профессиональным сообществам, недостаточно представлено в научной литературе.

Представлен лишь ряд научных публикаций, посвящённых общим принципам разработки педагогической диагностики для обеспечения учебно-воспитательного процесса отечественных исследователей А.С. Белкина, В.П. Беспалько, Л.Н. Давыдовой, Т.Г. Новиковой, Б.В. Тарева, Е.Г. Таревой, А.В. Хуторского, и др. В зарубежной литературе это работы Дж.К. Алдерсона, М. Гаррисона, Д. Бридсонга, К. Ван Дузера, К. Еркикан, К. Ингекампа, А. Тремблея, М.Д. Гаррисона, К.А. Чапеля и др., раскрывающих методы оценки уровня сформированности способности к коммуникации на английском языке. При этом исследователь К. Ингекамп выделяет наряду с лингводидактическим компонентом педагогическую составляющую образовательного процесса, которая, как он полагает, тоже требует разработки инструментов для оценки деятельности обучающегося. Такие инструменты могут быть разработаны в формате анкеты, а также в системе критериально-диагностических процедур, позволяющих описать поведение, объяснить мотивы или предсказать речевое поведение обучающегося в будущем [8]. 
Педагогическая экспертиза обеспечивает объективность, которую исследователи рассматривают как важнейший методологический принцип построения критериально-диагностического аппарата, предполагающего получение валидных данных об изучаемом педагогическом явлении в метрической системе с целью выявления эвристического показателя обученности студента. Такой показатель не может быть основан на каком-то одном критерии, а требует комплекса критериев, обусловленных многими факторами, которые выявляются на основе системного исследования.

При обзоре литературы по теме статьи мы пришли к выводу о необходимости разработать критериально-диагностический аппарат и другие оценочные средства, позволяющие исследователям и педагогам проводить эффективные диагностические процедуры для оценки деятельности обучающегося в условиях необходимости иноязычной коммуникации, в основе которой лежат дискурсивные практики.

\section{3. Методология исследования}

Большинство исследователей в сфере разработки диагностического инструментария акцентируют внимание на необходимости с помощью контрольно-измерительных процедур получать объективные результаты, отражающие качество и эффективность образовательного процесса. Диагностика педагогической технологии рассматривается, в частности, как обязательный элемент образовательного процесса, цель которого - достижение искомого результата. Диагностические процедуры, как отмечает А.В. Хуторской [12], необходимы для выявления, анализа, оценивания и корректировки педагогического процесса. Необходимость выделения критериев и способа диагностики процесса обучения отмечали также В.П. Беспалько [2], Н.Ф. Талызина [11] и др. Некоторые разработчики оценочных средств отмечают, что «В настоящее время в силу значительного внимания к коммуникативным компетенциям выпускников университетов адекватная оценка их уровня способности к коммуникации на иностранном языке становится одной из приоритетных задач высшего образования» [20].

В ходе разработки критериально-диагностического аппарата для оценки эффективности педагогического процесса, направленного на формирование способности будущих бакалавров к профессионально-ориентированной коммуникации на иностранном языке, в целях нашего исследования необходимо учесть следующие, которые позволяющие раскрыть лежащие в основе алгоритма реализации таких диагностических процедур методологические принципы.

В 1966 г. американский исследователь Р.Б. Каплан установил прямую взаимосвязь между мыслями представителей различных узусов и тем, как эти мысли выражаются в языке, выделив пять типичных моделей реализации речевой интенции в ходе коммуникации в зависимости от языковых групп: 1) англоязычной, 2) семитской, 3) восточной, 4) романской, 5) русской (рис.) [19].

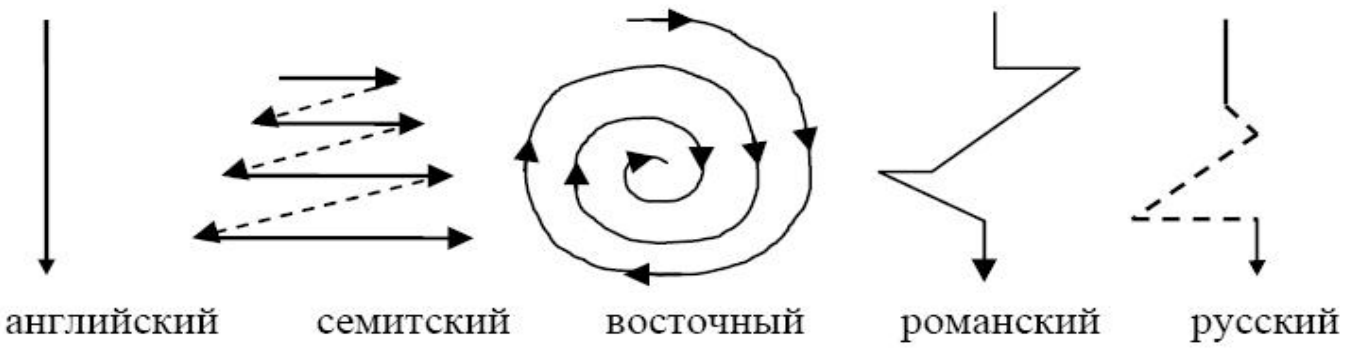

Рис. Модели реализации речевой интенции представителей различных языковых групп

Английская, или англоязычная модель речевого взаимодействия представляет собой ограниченную временными рамками линейную структуру, отражающую последовательность описываемых событий в их логической взаимосвязи. Такое высказывание характеризуется как жестко структурированное и завершённое.

Семитская модель речевого взаимодействия отражает узус семитской группы афразийской языковой семьи, а именно: жёстко кодифицированную норму речевого взаимодействия. Такая норма предполагает констатацию реалий объективного характера и последующее разъяснение позиции говорящего по отношению к этим реалиям. Последовательность констативов в определённой логике и динамике позволяет продуценту добиться цели коммуникации. Наглядным примером такого речевого взаимодействия могут быть библейские тексты. 
Некоторые аспекты разработки критериально-диагностического аппарата...

Для восточной модели речевого взаимодействия характерен центростремительный вектор. Нормой является условие «отягощения» коммуникации комплиментарным дискурсом, призванным заложить прочную основу для благоприятного исхода речевого взаимодействия созданием в ходе коммуникации дружеской атмосферы, выражения абсолютного уважения к партнёру по коммуникации (как правило, хозяин дома или принимающая сторона) прежде, чем будет заявлена цель локуции. Такое речевое взаимодействие требует значительного временного ресурса. Такая коммуникативная стратегия характерна для народов, проживающих на территории стран Азии и Ближнего Востока.

Романская модель речевого взаимодействия представлена ломаной линией, что графически отражает возможные смысловые девиации в ходе коммуникации. Тем не менее, коммуникант завершает локуцию в границах заданной в начале диалога темы, не слишком нарушая границы топик-фрейма.

Русская модель речевого взаимодействия также представлена ломаной линией, что графически отражает возможные смысловые девиации в ходе коммуникации, с той лишь разницей, что линия или ход коммуникации изобилуют разрывами, что может означать разного рода затруднения по мере речевого взаимодействия. Тем не менее, коммуникант завершает локуцию в границах заданной в начале диалога темы, не слишком нарушая границы топик-фрейма.

В наших целях для разработки средств диагностики уровня владения обучающимися одной из вышеперечисленных дискурсивных практик представляется интересным рассмотреть англоязычную модель речевого поведения [19] в качестве основной для успешного формирования способности будущих бакалавров к профессионально-ориентированной коммуникации на иностранном языке за счёт понимания и владения ими такой речевой стратегией подачи информации, которая способствует успешной реализации коммуникативных намерений и межличностного, и профессионального характера.

В 1975 г. исследователь Г.П. Грайс разработал основные принципы речевого взаимодействия, известные как дискурсивные законы, которые были им представлены как:

- максима объёма (высказывание должно быть максимально информативным, но не избыточным);

- максима качества (высказывание должно быть максимально точным и объективным в смысле содержания и не предлагать собеседнику констативы / утверждения, истинность которых может быть легко подвергнута сомнению);

- максима соответствия (высказывание должно соответствовать коммуникативной задаче и исключать смысловые девиации);

- максима восприятия (стратегия порождения высказывания должна тяготеть к ясности и четкости фразирования мысли отсутствием двусмысленности, краткостью, структурированностью, что определяет уровень комфорта аудитории при восприятии речевого произведения в целом) [6].

Англоязычная модель речевого взаимодействия может быть реализована за счет дискурсивных формул, позволяющих в различных дискурсивных сообществах эффективно решать широкий диапазон поставленных перед участниками речевого взаимодействия коммуникативных задач.

Все стратегии речевого взаимодействия сообразно англоязычной модели имеют линейный характер и соответствует жанровой схеме, предложенной У. Чейфом, «ориентация - завязка - кульминация - развязка (заключительный констатив) - кода» [16]. Такую структуру высказывания, как правило, можно упростить до «введение - развитие сюжета / основная часть - кульминация - заключение (заключительный констатив)». Линейная структура англоязычной модели речевого взаимодействия позволяет целевой аудитории легко декодировать кульминационный компонент локуции. В зависимости от сценарного замысла введение или заключение, как структурные компоненты, могут быть интегрированы непосредственно в тело основной части речевого произведения.

Итак, решение в условиях учебного занятия обучающимися широкого диапазона поставленных перед обучающимися коммуникативных задач на иностранном языке требует от них порождения речевых произведений или дискурсов, вписанных в англоязычную модель речевого взаимодействия, в границах которой реализуются основные принципы сотрудничества Г.П. Грайса. Будущие бакалавры должны продемонстрировать также умение в течение небольшого промежутка времени проанализировать и обобщить обстоятельства, относящиеся к их личному / квазипрофессиональному опыту и / или опыту дискурсивного сообщества, членами которого они планируют стать в скором будущем; сформировать тематический фрейм (топик); разработать сценарий речевого произведения в границах и с опорой на структуру поставленной перед ними коммуникативной задачи (вопроса); и породить устный / письменный дискурс, которому свойственны жесткая структура, целостность, завершённость и соотнесенность с опытом или профессиональными знаниями целевой аудитории и контек- 
стом среды коммуникации. Такое речевое взаимодействие будет иметь также ярко выраженный экстралингвистический фактор, возникающий ввиду обстоятельств, подробно описанных и систематизированных в работах, посвященных анализу дискурса и психолингвистике [7; 9].

\section{4. Результаты исследования}

Представленный выше подход позволяет нам определить англоязычную модель речевого взаимодействия как наиболее эффективный способ реализации дискурсивных практик, что отвечает целям и задачам высшего профессионального образования, так как существующие информационные ресурсы (печатные издания, ТВ, радио, Интернет-ресурсы), а также коммуникативные стратегии в рамках информационных обменов между представителями профессиональных сообществ тяготеют именно к формату подачи информации, сообразному англоязычной модели речевого взаимодействия.

Нами установлено, что наиболее распространёнными жанрами и функциональными стилями сферы устного делового общения являются расспрос / интервью; подготовка сообщения / доклада; дискуссия / обсуждение; компиляция / пересказ услышанного и / или прочитанного, а также интерпретация элементов предметно-изобразительного кода в сообразный среде коммуникации дискурс [4], что позволяет прийти к умозаключению о том, что эти жанры и функциональные стили делового общения предопределяют перечень основных типов коммуникативных задач, свойственных институциональному дискурсу.

Расспрос / интервью, по сути, - диалог и характеризуется он высокой активностью одного или нескольких участников речевого взаимодействия при постановке коммуникативных задач.

Сообщение / доклад представляет собой краткое изложение информации, определяемой условиями среды коммуникации, с целью ознакомить с этой информацией заинтересованный круг лиц.

Дискуссия / обсуждение, как правило, представляет собой рассмотрение какой-либо темы / вопроса с целью выявить сильные / слабые позиции оппонирующих сторон и в процессе речевого взаимодействия или по окончании его прийти к решению проблемы или взаимоприемлемому компромиссу.

Компилячия / пересказ услышанного и / или прочитанного представляет собой суждение на основе полученной извне информации (письменный и / или устный текст), в процессе которого продуцент рассуждает и приходит к выводу о том, каким образом полученная информация объясняет то или иное явление или событие окружающего мира, либо каким образом какое-либо явление или событие можно рассмотреть с позиции разных точек зрения на него в аспекте организации последующего эффективного профессионального или бытового взаимодействия.

Интерпретация элементов предметно-изобразительного кода (таблица, график, диаграмма, гистограмма и др.) в сообразный среде коммуникации дискурс требует от коммуниканта породить речевое произведение на иностранном языке через определённую жанровую схему с присущими ей компонентами англоязычной модели речевого взаимодействия: ориентащия - завязка - кульминация - развязка - кода [17].

Таким образом, мы полагаем, что критериально-диагностический аппарат ФОСа должен отражать многофакторную основу способности будущего бакалавра к воспроизводству англоязычной модели речевого взаимодействия в ходе решения широкого диапазона коммуникативных задач. Речевое произведение оценивается в параметрах: Общее описание; Способ подачи / презентации локуции, - что отражает способность и готовность студента к коммуникации; Лексико-грамматический, что отражает тезаурусный уровень организации языковой личности; Композиционное оформление, что предполагает знание широкого диапазона дискурсивных формул; Соответствие теме коммуникации.

Как отмечено выше, процесс формирования способности будущих бакалавров к профессионально-ориентированной коммуникации на иностранном языке за счёт дискурсивной иноязычной компетенции имеет многофакторную основу, компонентами которой являются: мотивационный (знать и понимать, зачем необходимо предпринять то или иное коммуникативное действие на иностранном языке, и иметь мотив для вступления в речевое взаимодействие); когнитивный (знать и уметь выделить значимую информацию для успешного личностного и профессионального речевого взаимодействия на иностранном языке); деятельностный (знать и понимать, какое речевое действие (дискурсивная формула) должно быть реализовано в той или иной ситуации коммуникации на иностранном языке); и личностный (знать и понимать необходимость принятия решения в отношении выбора той или иной стратегии речевого поведения, чтобы добиться успешного завершения коммуникации на иностранном языке, избежать коммуникативного сбоя и не допустить смысловой девиа- 
Некоторые аспекты разработки критериально-диагностического аппарата...

ции). Такой подход позволяет рассмотреть многофакторность процесса коммуникации как систему критериев (мотивационный, когнитивный, деятельностный, личностный) готовности будущего бакалавра в ходе взаимодействия на иностранном языке следовать дискурсивным практикам с целью успешного решения задач коммуникативной направленности.

Диагностика мотивационного критерия позволяет выявить степень способности и готовности будущих бакалавров к коммуникации на иностранном языке с использованием существующих дискурсивных практик. Ранжирование системы уровней представлено как пороговый, продвинутый и высокий.

Диагностика когнитивного критерия отражает понимание будущими бакалаврами того, в какой ситуации коммуникации они находятся и какая дискурсивная практика должна быть применена с учётом регистра, типа, жанра, функциональности и формальности дискурса [10]. Диагностика когнитивного критерия проводится в ходе всего периода образовательного процесса на фоне работы преподавателя, направленной на решение проблемы непонимания обучающимися учебного материала через обратную связь в формате вопрос-ответ и в режиме тренировочных упражнений. Используется метод наблюдения. Ранжирование системы уровней представлено как пороговый, продвинутый и высокий.

Для диагностики деятельностного критерия мы предлагаем студентам последовательно решить комплекс задач коммуникативной направленности, чтобы выявить, насколько успешно они осуществляют коммуникацию на иностранном языке за счёт соотнесённых с коммуникативной задачей дискурсивных практик. Ранжирование системы уровней представлено как пороговый, продвинутый и высокий.

Диагностика личностного критерия позволяет выявить степень способности и готовности обучающегося осуществлять успешную профессионально-ориентированную коммуникацию на иностранном языке, а также уровень эрудированности студента при продуцировании условно-речевых и собственно-речевых произведений. Ранжирование системы уровней представлено как пороговый, продвинутый и высокий.

Уровень сформированности дискурсивной иноязычной компетенции будущих бакалавров как дескриптора их способности к профессионально-ориентированной коммуникации на иностранном языке оценивается в универсальной системе:

- пороговый: обучающиеся недостаточно мотивированы к коммуникации на иностранном языке; не предпринимают попытки решить поставленную перед ними коммуникативную задачу либо их попытки не имеют успеха, так как студенты слабо осознают практикоприменимость дискурсивных формул для решения поставленной перед ними коммуникативной задачи на иностранном языке; личностные качества, такие, как культура речи, кругозор, эрудиция и др., не позволяют обучающимся высказаться сообразно узусу страны изучаемого языка и наполнить своё речевое произведение содержанием в соответствии со смыслом коммуникативной задачи; коммуникант допускает грубые ошибки лексико-грамматического характера; высказывание не структурировано, не обладает целостностью и завершённостью;

- продвинутый: будущие бакалавры мотивированы к речевому взаимодействию на иностранном языке; их высказывание соответствует целям и задачам коммуникации, но может быть структурно не завершено; высказывание, в целом, содержит понятные целевой аудитории связанные друг с другом смыслы, межкультурный аспект которых легко декодируется, но связь между эпизодами высказывания иногда неочевидна; коммуникант демонстрирует такие личностные качества как знание и понимание речевого этикета, широкий кругозор, хорошую эрудицию; коммуникант может допустить ошибки лексико-грамматического характера; в речи могут присутствовать паузы; его высказывание на иностранном языке в основном соответствует принципам сотрудничества Г.П. Грайса;

- высокий: будущие бакалавры мотивированы и готовы к коммуникации на иностранном языке; их высказывание соответствует целям и задачам коммуникации, в нём учтён межкультурный аспект коммуникации; могут присутствовать лишь незначительные недостатки, касающиеся полноты и завершённости высказывания; коммуникант может допустить незначительные ошибки лексикограмматического характера, которые не приводят к искажению смысла высказывания; речевое произведение построено сообразно англоязычной модели речевого взаимодействия, отражает широкий кругозор и высокую степень эрудированности коммуниканта и соответствует принципам сотрудничества Г.П. Грайса. 
Нами установлена соотнесённость параметров оценки качества продуктов речевой деятельности обучающихся и критериев сформированности дискурсивной иноязычной компетенции (табл.), что позволяет провести универсифицированную диагностическую процедуру и на разных этапах определения уровня сформированности данной компетенции получить непротиворечивые достоверные данные в системе традиционной пятибалльной шкалы ранжирования. Более развёрнутое описание параметров оценки качества речевого произведения дано в ранее опубликованной работе [5. С. 137].

Система соотнесённости параметров оценки качества речевого произведения и уровней критериев сформированности дискурсивной иноязычной компетенции в сфере устного общения

\begin{tabular}{|c|c|}
\hline $\begin{array}{l}\text { Параметр оценки качества } \\
\text { речевого произведения }\end{array}$ & $\begin{array}{l}\text { Критерий и уровень ранжирования готовности студента } \\
\text { следовать дискурсивным практикам }\end{array}$ \\
\hline $\begin{array}{l}\text { Общее описание (обобщает содержание } \\
\text { параметров оценки). }\end{array}$ & $\begin{array}{l}\text { Мотивационный, когнитивный, деятельностный, лич- } \\
\text { ностный. }\end{array}$ \\
\hline $\begin{array}{l}\text { Традиционная 5-ти балльная шкала оценки: } \\
5 \text { - высокий; } \\
4-3 \text { - продвинутый; } \\
\text { 2-0 - пороговый. }\end{array}$ & $\begin{array}{l}\text { Уровни критерия: } \\
\text { Высокий; } \\
\text { Продвинутый; } \\
\text { Пороговый. }\end{array}$ \\
\hline $\begin{array}{l}\text { Традиционная 5-ти балльная шкала оценки: } \\
5 \text { - высокий; } \\
\text { 4-3 - продвинутый; } \\
\text { 2-0 - пороговый. }\end{array}$ & $\begin{array}{l}\text { Мотиваиионныци (коммуникант знает и понимает, } \\
\text { с какой целью должно состояться речевое } \\
\text { взаимодействие) } \\
\text { Когнитивный (коммуникант демонстрирует знание и } \\
\text { понимание системных характеристик дискурса) } \\
\text { Деятельностный (коммуникант знает и понимает, какое } \\
\text { речевое действие необходимо предпринять) } \\
\text { Уровни критерия: } \\
\text { Высокий; } \\
\text { Продвинутый; } \\
\text { Пороговый. }\end{array}$ \\
\hline $\begin{array}{l}\text { Лексико-грамматический } \\
\text { (отражает тезаурусный уровень организации } \\
\text { языковой личности) } \\
\text { Традиционная 5-ти балльная шкала оценки: } \\
5 \text { - высокий; } \\
4-3 \text { - продвинутый; } \\
\text { 2-0 - пороговый. }\end{array}$ & $\begin{array}{l}\text { Личностный (коммуникант обладает определённым } \\
\text { корпусом лексических единиц и грамматических } \\
\text { структур) } \\
\text { Когнитивный (коммуникант (не) демонстрирует } \\
\text { широкий кругозор и эрудицию) } \\
\text { Уровни критерия: } \\
\text { Высокий; } \\
\text { Продвинутый; } \\
\text { Пороговый. }\end{array}$ \\
\hline $\begin{array}{l}\text { Композииионное оформление (предполагает } \\
\text { знание широкого диапазона дискурсивных } \\
\text { формул) } \\
\text { Традиционная 5-ти балльная шкала оценки: } \\
\text { 5- высокий; } \\
\text { 4-3 - продвинутый; } \\
\text { 2-0 - пороговый. }\end{array}$ & $\begin{array}{l}\text { Мотивационный (коммуникант использует дискурсив- } \\
\text { ные знания, мотивирован на обращение к известным ему } \\
\text { дискурсивным практикам / дискурсивным формулам) } \\
\text { Когнитивный (коммуникант знает и понимает, почему } \\
\text { необходимо использовать ту или иную дискурсивную } \\
\text { формулу) } \\
\text { Уровни критерия: } \\
\text { Высокий; } \\
\text { Продвинутый; } \\
\text { Пороговый. }\end{array}$ \\
\hline $\begin{array}{l}\text { Соответствие теме коммуникаичи } \\
\text { Традиционная 5-ти балльная шкала оценки: } \\
\text { 5- высокий; } \\
\text { 4-3 - продвинутый; } \\
\text { 2-0 - пороговый. }\end{array}$ & $\begin{array}{l}\text { Личностный (коммуникант демонстрирует определён- } \\
\text { ный кругозор и эрудицию в соответствии с темой ком- } \\
\text { муникативной задачи; способен разработать и соответ- } \\
\text { ствовать топику-фрейму коммуникативной задачи) } \\
\text { Уровни критерия: } \\
\text { Высокий; } \\
\text { Продвинутый; } \\
\text { Пороговый. }\end{array}$ \\
\hline
\end{tabular}


Некоторые аспекты разработки критериально-диагностического аппарата...

Более развёрнутое описание соотнесённости критериев и уровней ранжирования готовности студента следовать дискурсивным практикам дано в ранее опубликованной работе [5. С. 133].

\section{5. Обсуждение результатов исследования}

Критериально-диагностический аппарат исследования был апробирован в ходе экспериментальной работы, направленной на развитие способности будущих бакалавров к профессиональноориентированной коммуникации на иностранном языке за счёт формирования дискурсивной иноязычной компетенции в сфере устного общения.

Результаты исследования реализованы в системе диагностических процедур для промежуточного и итогового контроля уровня сформированности дискурсивной иноязычной компетенции будущих бакалавров на различных направлениях подготовки Института психологии, педагогики и социальных технологий, Института истории и социологии, Института языка и литературы Удмуртского государственного университета (г. Ижевск). Как отмечено выше, такая компетенция нами рассмотрена как дескриптор способности будущих бакалавров к профессионально-ориентированной коммуникации на иностранном языке.

Опыт практической работы свидетельствует в пользу того, что технологизация содержания диагностических процедур позволяет преподавателю в значительной степени упростить диагностику уровней сформированности искомой компетенции и получить отражающие реальное положение дел данные в системе традиционной пятибалльной шкалы ранжирования, которые мы рассматриваем как достоверные и приемлемые для обобщения полученных в ходе исследования результатов. Необходимость получения достоверных и приемлемых данных отмечается и отечественными, и зарубежными исследователями (Дж. Алдерсон [14], К. Чапел [18], А. Тремблей, М. Гаррисон [21], Д. Бридсонг [15]).

Результаты отражены в итоговой части экспериментальной работы проведённого нами исследования, в рамках которого на разных этапах были затранскрибированы ответы студентов в соответствии с поставленными перед ними коммуникативными задачами. Заявленный в рамках экспериментальной работы диапазон коммуникативных задач и разработанные нами диагностические процедуры позволяют выявить уровень сформированности способности студентов к профессиональноориентированной коммуникации на иностранном языке за счёт дискурсивной иноязычной компетенции и перевести полученные результаты в систему традиционной метрической (пятибалльной) шкалы оценки для последующего обобщения.

Такой эвристический подход мы находим целесообразным, так как цель разработки заявленных нами диагностических процедур не в получении математически точной оценки уровня способности к профессионально-ориентированной коммуникации на иностранном языке, но в обеспечении достоверности и приемлемости полученных данных, что обусловливает возможность для исследователя продемонстрировать наличие или отсутствие положительной динамики в ходе образовательного процесса.

Обсуждение результатов исследования состоялось в формате докладов на международных научно-практических конференциях, а также через размещение информации о сделанных нами выводах в открытых источниках, в том числе в рецензируемых научных изданиях, рекомендованных ВАК Министерства науки и высшего образования РФ.

\section{6. Заключение}

Статья отражает некоторые подходы к разработке критериально-диагностических процедур для оценки уровня сформированности дискурсивной иноязычной компетенции как дескриптора способности будущих бакалавров к профессионально-ориентированной коммуникации на иностранном языке. В основе такой способности лежит дискурсивная составляющая. Нам представляется методологически обоснованным рассмотреть содержательную часть коммуникации как реализацию речевых намерений коммуникантов. Следуя определению, данному Н.Д. Арутюновой, «Дискурс - это речь, «погруженная в жизнь» [1. С. 136], мы определили, что англоязычная модель речевого взаимодействия как способ реализации речевой интенции на иностранном языке (или порождение дискурса на иностранном языке), удовлетворяет нашей цели определить предмет оценки и разработать систему её параметров простым и удобным алгоритмом диагностических процедур. В статье представлены обоснование и унифицированный подход к разработке такого алгоритма для технологизации непосредственно самого процесса оценивания уровня способности будущих бакалавров к профессионально-ориентированной коммуникации на иностранном языке. 
Такая система оценки включает: 1) понимание целесообразности выбора англоязычной модели речевого взаимодействия как наиболее прагматичной модели коммуникации; 2) разработку системы параметров оценки качества речевого произведения; 3) соотнесение этой системы с критериями и уровнем ранжирования готовности студента следовать дискурсивным практикам.

Заявленная система оценки понятна и преподавателю, и студентам; она позволяет всем им проводить диагностику и самодиагностику способности порождать дискурсы, соответственно.

Результаты экспериментальной работы, в ходе которой были реализованы заявленные критериально-диагностические процедуры, подтверждают эффективность такой диагностической технологии и возможность её приращения дополнительными оценочными средствами.

\section{СПИСОК ЛИТЕРАТУРЫ}

1. Арутюнова Н.Д. Дискурс // Лингвистический энциклопедический словарь. М.: Советская энциклопедия. $1990.688 \mathrm{c}$.

2. Беспалько В.П. Слагаемые педагогической технологии. М.: Педагогика, 1989. 192 с.

3. Глухов Г.В. Теория и методика проектирования содержания германских языков в системе высшего профессионального образования: дис. ... докт. пед. наук: 13.00.08. Тольятти. 2000. 438 с.

4. Горбунов А.Г., Ворожцова И.Б. Интерпретация предметно-изобразительного кода через создание дискурса в условиях учебного занятия в вузе // Вестн. Удм. ун-та. Сер. Философия. Психология. Педагогика. 2017. № 3. C. 358-364.

5. Горбунов А.Г. Педагогическая система формирования способности будущих бакалавров к иноязычной профессионально-ориентированной коммуникации: монография. Ижевск: Изд. центр «Удмуртский университет». 2018. $196 \mathrm{c}$.

6. Грайс, Г.П. Логика и речевое общение // Новое в зарубежной лингвистике. Bып. XVI. M.: Прогресс. 1985. С. 217-237.

7. Зимняя И.А. Лингвопсихология речевой деятельности. М.: Московский психолого-социальный институт, Воронеж: НПО МОДЭК. 2001. 432 с.

8. Ингекамп К. Педагогическая диагностика. М.: Педагогика, 1999. 240 с.

9. Карасик В.И. Языковой круг: личность, концепты, дискурс. Волгоград: Перемена. 2004. 390 с.

10. Кибрик А.А. Модус, жанры и другие параметры классификации дискурсов // Вопросы языкознания. 2009. № 2. C. 3-21.

11. Талызина Н.Ф. Педагогическая психология. М.: Айрис-пресс. 2006. 112 с.

12. Хуторской А.В. Технология эвристического обучения // Новые технологии. 1998 г. № 4. С. 55-75.

13. Поручение Президента Российской Федерации (Пр-294, п.2а-16) «Обновление федеральных государственных образовательных стандартов и примерных основных образовательных программ, в том числе с учётом приоритетов научно-технологического развития Российской Федерации» от 04.03.2019.

14. Alderson J.C. 1979. The cloze procedure and proficiency in English as a foreign language. TESOL Quarterly. Issue 13. pp. 219-227.

15. Birdsong D. 2005. Interpreting age effects in 2nd language acquisition. In Kroll, J. \& de Groot, A. (Eds.). Handbook of bilingualism (pp. 109-127). Oxford: Oxford University Press.

16. Chafe W. 1982. Integration and involvement in speaking, writing, and oral literature. In spoken and written language: Exploring orality and literacy. Ed. D. Tannen. Norwood: Ablex. pp. 35-54.

17. Chafe W. 1994. Discourse, consciousness, and time. The flow and displacement of conscious experience in speaking and writing. Chicago: University of Chicago Press. 327 p.

18. Chapelle C.A. 1999. Validity in language assessment. Annual Review of Applied Linguistics. Issue 19. pp. 254-272.

19. Kaplan R.B. 1966. Cultural thought patterns in intercultural education. Language Learning. № 16. pp. 1-20.

20. Tarev B.V., Tareva E.G. 2018. The assessment of students' professional communicative competence: New challenges and possible solutions. XLinguae. Issue 11 (2). pp. 758-767. DOI: 10.18355/XL.2018.11.02.59

21. Tremblay A., Garrison M.D. 2010. Cloze tests: A tool for proficiency assessment in research on L2 French. In Prior, M.T., Watanabe Y., \& Lee S.-K. (Eds.). Selected proceedings of the Second Language Research Forum 2008 (pp. 73-88). Somerville, MA: Cascadilla Press.

Горбунов Анатолий Геннадьевич, старший преподаватель кафедры

лингвистического и лингводидактического сопровождения

иноязычной профессиональной коммуникации Института языка и литературы

ФГБОУ ВО «Удмуртский государственный университет»

426034, Россия, г. Ижевск, ул. Университетская, 1

E-mail: votkaizhevsk@yandex.ru 


\section{A.G. Gorbunov \\ SOME ASPECTS OF DIAGNOSTIC POCEDURES DEVELOPMENT TO ESTIMATE THE LEVEL OF ABILITY OF FUTURE BACHELORS OF HUMANITIES TO PROFESSIONALLY ORIENTED COMMUNICATION IN A FOREIGN LANGUAGE}

DOI: $10.35634 / 2412-9550-2019-29-4-478-487$

In the context of a continuously changing educational environment the problem of development of its content and sets of criteria for diagnostic procedures in the framework of a students' performance assessment system shall never lose its relevance. In particular, an assessment system to determine the level of proficiency in professionally oriented foreign language communication in future bachelors in humanities has been considered within the modern pedagogic methodology that suggests synergy of various scientific knowledge. The aim of the article is to consider and describe some aspects of assessment procedures development as an effective means to estimate the level of future bachelors' capacity for professionally oriented communication in a foreign language through perception and production of discourses which are common for various professional communities. Methodology and research methods. The review of the information resources leads us to the conclusion that presentation strategies in the media (TV, periodicals, the Internet, etc.) and within information exchanges between representatives of professional communities tend to the English language model of verbal interaction that is linear, has a pronounced structure and strict logics as well as a characteristic of a complete locution. The latest achievements in the applied linguistics make it possible to state that communication is based on the ability of locutors to interpret and produce discourses. Such approach to understanding of the discursive nature of communication resulted into a universal system of diagnostic procedures to provide in the traditional five-point rating scale assessment a certain level of validity and acceptability when formation of discursive foreign language competence as a descriptor of the level of proficiency of future bachelors in professionally oriented communication in a foreign language is concerned. Results and scientific novelty. Based on synergy of data from different sciences the algorithm of the diagnostic and assessment procedures in question makes it possible to obtain valid figures. The algorithm has been tested in the course of experimental work and proved its efficiency. Practical significance. The set of criteria for diagnostic procedures is found to have a high flexibility and assumed to integrate additional assessment means.

Keywords: students' performance assessment system, set of criteria for diagnostic procedures, assessment procedure, communicative foreign language competence, discursive foreign language competence, English language model of verbal interaction.

Received 13.08.2019

Gorbunov A.G., Senior lecturer at Department of Linguistic and Lingual-Didactic Provision

for Foreign Language Professionally Oriented Communication Development

at the Institute of Language and Literature

Udmurt State University

Universitetskaya st., 1, Izhevsk, Russia, 426034

E-mail: votkaizhevsk@yandex.ru 